\title{
Religião, laicidade e direitos sexuais e reprodutivos: a presença de grupos religiosos conservadores nos espaços públicos da contemporaneidade
}

\author{
Celso Gabatz*
}

\section{Resumo}

Este artigo tem o propósito de aprofundar algumas questões acerca da presença de grupos religiosos conservadores na arena pública brasileira e os efeitos desta crescente intervenção sobre os direitos das mulheres, no campo da reprodução e do livre exercício da sexualidade. Os resultados apontam que a laicidade deveria ser respaldada pelo reconhecimento da diversidade cultural e religiosa de modo a ampliar a liberdade de expressão, suplantar possíveis acirramentos e consolidar políticas democráticas. $\mathrm{O}$ grande desafio que se impõe é o de deixar de lado possíveis extremismos religiosos ou laicos em detrimento da tolerância, do diálogo e do mútuo aprendizado entre os diversos protagonistas que articulam o debate.

Palavras-chave: Religião, Laicidade; Direitos Sexuais e Reprodutivos.

\section{Religion, secularism and sexual, reproductive rights: The presence of religious conservative groups in public spaces of contemporaneity}

\section{Abstract}

This paper intends to consider in greater detail some issues regarding the presence of conservative religious groups in the Brazilian public arena and the effects of this increasing intervention on women's rights, particularly in the field of reproduction and free exercise of sexuality. The results show that secularism should be supported by the recognition of cultural and religious diversity in order to increase freedom of expression, overcome eventual conflicts and consolidate democratic policies. The great

\footnotetext{
Doutorando no Programa de Pós-Graduação em Ciências Sociais da Universidade do Vale do Rio dos Sinos (UNISINOS), São Leopoldo-RS. Mestre em História Regional pelo Programa de Pós-Graduação em História da Universidade de Passo Fundo (UPF). Bolsista vinculado à Coordenação de Aperfeiçoamento de Pessoal de Nível Superior - CAPES. E-mail: <gabatz@uol.com.br>
} 
challenge that lies ahead is to put aside any religious or secular extremisms so as to promote tolerance, dialogue and mutual learning between the different actors engaged in this debate.

Keywords: Religion, Secularism, Sexual and Reproductive Rights

\section{Religión, laicidad y derechos sexuales y reproductivos: la presencia de los grupos religiosos conservadores en los espacios públicos de la contemporaneidad}

\section{Resumen}

Este artículo tiene el propósito de profundizar algunas preguntas acerca de la presencia de los grupos religiosos conservadores en la arena pública brasileña y los efectos de esta creciente intervención sobre los derechos de las mujeres en el campo de la reproducción y el libre ejercicio de la sexualidad. Los resultados indican que la laicidad debe ser respaldada por el reconocimiento de la diversidad cultural y religiosa, con el fin de ampliar la libertad de expresión, suplantar posibles resurgimientos y consolidar políticas democráticas. El principal reto es dejar de lado los extremismos religiosos o laicos, en detrimento de la tolerancia, del diálogo y el mutuo aprendizaje entre los diversos protagonistas que articulan el debate.

Palabras clave: Religión, Laicidad; Derechos Sexuales y Reproductivos.

\section{Considerações Iniciais}

As discussões em torno da laicidade encontram-se diretamente pautadas pela presença da religião nas esferas da política representativa, impedindo que o Estado brasileiro cumpra a sua função constitucional de forma plena e eficaz, uma vez que grupos religiosos interferem, na maioria das vezes, em propostas relacionadas com a ampliação dos direitos sexuais e reprodutivos.

É importante aprofundar as circunstâncias e motivos pelos quais alguns grupos religiosos têm agido de maneira incisiva e ambivalente em um cenário caracterizado pela 'desinstitucionalização' das religiões. De igual forma, cumpre destacar que esta pauta faz com que a arena política se torne um espaço constante de disputas, reforçando a pergunta pelos limites aceitáveis da liberdade religiosa, nem sempre associada à plena conformidade dos direitos humanos a todos os grupos sociais.

Assim como a laicidade, os direitos sexuais e reprodutivos também se inserem no âmbito de uma compreensão moderna da autonomia individual e das liberdades privadas. O exercício de direitos envolve as liberdades pessoais que, por sua vez, estimulam a perspectiva das obrigações sociais. Estas envolvem o âmbito público, uma vez que é o Estado que deve garantir as 
condições adequadas e capazes de assegurar que os direitos sejam exercidos de maneira segura e equitativa, por todos os seus cidadãos e cidadãs.

\section{Laicidade e Liberdade Religiosa no Brasil Contemporâneo}

A laicidade diz respeito a uma separação entre religião e Estado. O Estado se apresenta como neutro em termos confessionais. As instituições do Estado também são autônomas em relação à religião. Elas não devem ser submissas aos valores, desejos e interesses religiosos. O Estado deve garantir o mesmo tratamento a todas as confissões religiosas e garantir a liberdade de expressão também aos que não creem. "O Estado é (...) neutro em relação aos grupos, tolerando a todos, e autônomo em seus objetivos" (BERGER, 2004, p. 119).

De acordo com Daniel Sarmento a laicidade adotada na maioria das democracias contemporâneas opera em duas direções:

Por um lado ela salvaguarda as diversas confissões religiosas do risco de intervenções abusivas do Estado nas suas questões internas, concernentes a aspectos como os valores e doutrinas professados, a forma de cultuá-los, a sua organização institucional, os seus processos de tomada de decisões, a forma e o critério de seleção de seus sacerdotes e membros (...). Mas, de outro lado, a laicidade também protege o Estado de influências indevidas provenientes da seara religiosa, impedindo todo tipo de confusão entre o poder secular e democrático, em que estão investidas as autoridades públicas, e qualquer confissão religiosa, inclusive majoritária (SARMENTO, 2008, p. 190-191).

É salutar observar que a laicidade não significa a adoção pelo Estado de uma posição ateísta ou resistente à religiosidade. O ateísmo também não deixa de ser uma crença religiosa que não pode ser privilegiada pelo Estado em detrimento de outra compreensão. A laicidade incumbe o Estado para que este se mantenha neutro diante de diferentes concepções religiosas sem tomar partido, favorecer ou dificultar qualquer crença (FONSECA, 2013).

A laicidade pode ser diretamente relacionada a dois direitos fundamentais do constitucionalismo contemporâneo: igualdade e liberdade de crença (CANOTILHO, 1993). Em uma sociedade pluralista como a brasileira, com tantas crenças e opções religiosas, o princípio da igualdade converte-se em um instrumento indispensável ao tratamento de todos os seus indivíduos com respeito e equidade. Já em relação à liberdade religiosa individual, ainda que haja garantia constitucional, a laicidade caracteriza-se como uma diretriz capaz 
de interditar a promiscuidade entre os poderes públicos e algumas doutrinas religiosas (MARTINS FILHO e NOBRE, 2011).

A consagração da liberdade religiosa como um direito civil básico relacionada à liberdade de expressão, no mundo ocidental, encontra grande destaque na obra de John Locke, para quem o "problema da intolerância" resultava da confusão entre os domínios civil e religioso. Em seu livro Carta a respeito da tolerância, Locke estabeleceu as bases para o princípio da laicidade do Estado ao indagar "até onde se estende o dever de tolerância, e o que se exige de cada um por este dever?" (LOCKE, 1964. p. 17) e que "pessoa alguma tem o direito de prejudicar de qualquer maneira a outrem nos seus direitos civis por ser de outra igreja ou religião" (LOCKE, 1964, p. 18). Deste modo, propôs que a força política do Estado somente deveria intervir no funcionamento ou regulamentar os cultos quando estes se revelassem atentatórios ao direito das pessoas ou ao funcionamento da sociedade.

Rui Barbosa, por exemplo, considerou a liberdade religiosa como a mais importante das liberdades sociais. "De todas as liberdades sociais, nenhuma é tão congenial ao homem, e tão nobre, e tão frutificativa, e tão civilizadora, e tão pacífica, e tão filha do Evangelho, como a liberdade religiosa" (BARBOSA, 1877, p. 419). A liberdade religiosa, enquanto direito fundamental, supõe a complexidade de vertentes subjetivas e objetivas, individuais e coletivas, de dimensões negativas e positivas, vinculando-se aos entes públicos e privados com manifestações de crença e culto, de ordem institucional e procedimental. Por tratar-se de um direito fundamental, deveria ser interpretado sob o prisma da liberdade e não sob o enfoque teológico de uma 'verdade' (WEINGARTNER, 2007, p. 61).

É importante salientar que a doutrina constitucionalista brasileira não oferece uma orientação segura a respeito da liberdade religiosa. Em geral, a análise reveste-se de um caráter formalista, limitado pela apresentação genérica de uma ideia sem ressaltar a importância do direito em destaque (LEITE, 2014). Neste sentido, discutir a liberdade religiosa no Brasil passa por alguns assuntos como a questão da presença dos símbolos religiosos nos espaços públicos, a presença do ensino religioso nas escolas púbicas, feriados religiosos e respeito aos dias de guarda, assistência religiosa confessional no âmbito de instituições públicas, imunidade tributária, cooperação entre igrejas e Estado e, de forma especial, a influência política de alguns grupos religiosos nas instâncias deliberativas de poder (RODRIGUES, 2014). 
De acordo com Jónatas Machado (2013) a liberdade religiosa situa-se no discurso jurídico-constitucional tendo como premissa e valor de igual dignidade e liberdade de todos os cidadãos, procurando apresentar um conceito de religião e de liberdade religiosa dotado de um grau de inclusão compatível com aqueles valores que afastem dos domínios das opções de fé e da vivência religiosa qualquer forma de coerção e discriminação jurídica ou social.

O exercício da liberdade religiosa individual e coletiva supõe a proteção do exercício da liberdade de associação religiosa em sentido amplo, incluindo a constituição de pessoas coletivas de natureza e finalidade religiosa dotadas dos necessários direitos de auto definição doutrinal e autodeterminação moral e auto governo institucional (...). O Estado tem que ser garantidor de igual dignidade e liberdade de todos os cidadãos e grupos de cidadãos, religiosos ou não (MACHADO, 2013, p. 146).

Elsa Galdino (2006) afirma que o Brasil estabeleceu uma concepção hierárquica e desigual a respeito da construção de um espaço público laico que permitiu a constituição de uma arena pública, na qual as regras de acesso aos bens disponibilizados pelo Estado não são gerenciadas de forma universalista e igualitária para todos os credos. Tal situação gerou uma espécie de dissonância entre as regras impessoais e universais impostas pela esfera pública e os princípios hierárquicos, desiguais e personalistas presentes na esfera e no espaço público brasileiro.

A inexistência de um princípio universalista e de tratamento igual e uniforme que abrangesse todos os sistemas religiosos inviabilizou o pleno reconhecimento dos direitos de certas matrizes religiosas, promovendo o acesso particularizado e desigual de determinadas religiões ao espaço público brasileiro, como se um sistema religioso fosse mais legítimo que o outro (DAMATTA, 1986). Desta maneira, mesmo com o movimento de laicização do Estado brasileiro, "em nenhum momento ou lugar, as religiões deixaram de ser uma "questão de Estado"” (MONTERO e ALMEIDA, 2000, p. 326).

Danièle Hervieu-Léger (2008) se vale da teoria weberiana para explicar o novo papel da religião. Para a pesquisadora francesa, as crenças teriam afinidades eletivas em relação ao ethos econômico e social. O que acontece na contemporaneidade seria uma aceitação de afinidades eletivas entre a individualidade religiosa e a individualidade da vida moderna. Hervieu-Léger parte do reconhecimento da dificuldade em delimitar com clareza o conceito 
de religião tendo em vista o dado de uma fragilização das separações entre sagrado e profano nas sociedades modernas.

$\mathrm{Na}$ mesma direção delineada por Hervieu-Léger, um dos precursores da ideia da construção social da realidade, Thomas Luckmann, (2014), refere que a religião se torna invisível na contemporaneidade e dissemina-se de forma difusa, fazendo com que suas manifestações extrapolem os limites restritos dos espaços convencionais, deslocando-se para outras áreas da vida humana em sociedade, como a política e a mídia. Neste sentido, múltiplas são as possibilidades de expressão sem seguir os contornos demarcados pelas instituições. Forja-se um horizonte de vastas possibilidades onde, de acordo com Paulo Barrera Rivera:

Nas sociedades contemporâneas não há mais campo religioso estável, e os compromissos de longa duração deixaram de ser norma. Diversos tipos de opções religiosas e múltiplos produtos religiosos são oferecidos dia a dia nos templos e nos meios de comunicação. Religião exclusiva é coisa do passado. O sagrado apresenta-se multiforme, pouco hegemônico e, sobretudo, em constante movimento (RIVERA, 2003. p. 438).

Uma das questões pertinentes na discussão em pauta é a partir de quais referências poderia ser possível compreender com maior clareza as profundas mudanças ocorridas no campo religioso brasileiro (FISCHMANN, 2008)? De igual forma, qual o sentido das repercussões nos usos e as apropriações do espaço público por uma religiosidade historicamente consolidada (ORTIZ, 2001)? Qual o papel ocupado pela religião em meio às transformações da sociedade moderna (MARTELLI, 1995)?

\section{O Ativismo Conservador na Esfera Pública Brasileira}

Os desafios, demandas e possibilidades, entabuladas no âmbito do pluralismo religioso na realidade brasileira contemporânea, reforçam a articulação de grupos "conservadores" que embasam as suas ações sublinhadas pelo entendimento de que a modernidade fez emergir a decadência moral, social, cultural e política. Esta decadência estaria diretamente ligada a um "liberalismo teológico" dos movimentos de esquerda, a suposta subversão promovida pelo feminismo, o crescimento da "libertinagem sexual", a ameaça das facções políticas "comunistas", o afrouxamento das autoridades, das leis, da punição aos infratores e o aumento da criminalidade. 
As identidades "conservadoras" premissas de restauração de um movimento mítico original, quer seja, a "cristandade", a "sociedade", as "comunidades autênticas" ou a "igreja fiel ou heroica" (BEATY, 2014). Também faz alusão à emergência de ditaduras totalitárias que levariam à perseguição e martírio dos cristãos, dos "homens e mulheres de bem". Daqueles e daquelas que "sentem-se chamados" a defender a "verdadeira família" (MALAFAIA, 2012). Uma defesa intransigente com rescaldos de belicosidade.

É importante destacar que a articulação de grupos conservadores, nas últimas décadas, é uma referência imprescindível para compreender os contornos das sensibilidades religiosas contemporâneas, na perspectiva dos direitos sexuais e reprodutivos (CATROGA, 2006). A multiplicação dos espaços de atividades religiosas, o espetáculo das massas, a penetração de agentes religiosos em todos os níveis do estado, acabou por criar novas demandas em relação à força persuasiva da imagem do Brasil como nação católica, além de conferir novos instrumentos de poder e de influência na formação da opinião pública, modificando a percepção sobre o que corresponde ao interesse coletivo (SANTOS, 2003).

Cabe ressaltar que a realidade brasileira contemporânea tem repercutido inúmeras situações marcadas pelos dilemas das diferenças. O aparecimento de reivindicações com base na diferença traz à tona uma reflexão e uma disputa, muitas vezes veemente, sobre o lugar, os direitos, as representações, a vez e a voz das minorias. A diferença não pode ser compreendida apenas

\footnotetext{
Há uma dificuldade teórica em classificar estes grupos. Em algumas abordagens são chamados de fundamentalistas por utilizarem, com frequência, critérios bíblicos, por vezes, literais, para sustentar suas posições. No entanto, as referências a estes grupos são cada vez mais seculares, pois é comum utilizarem também terminologias ligadas ao direito, economia, ciências médicas e biológicas. Percebe-se que não há tanto empenho em argumentar publicamente com base apenas em razões teológicas, mas, muito mais a partir de um sentido de preservação moral e dos bons costumes. É um discurso que apela mais para os valores civis e a democracia, ainda que esta seja interpretada de forma bastante particular. A pesquisadora Jaris Mujica que é vinculada ao Centro de Promoção e Defesa dos Direitos Sexuais e Reprodutivos em Lima, no Peru, refere que: "O ativismo conservador que defende as tradições, (...)] penetrou estrategicamente no secular. Isso obriga a pensa-lo de maneira diferente e a repensar a figura do fundamentalismo religioso. É preciso considerar que o olhar que se teve sobre o fundamentalismo criou imagens essenciais desses grupos e evitou o registro de suas práticas e estratégias, gerando estereótipos. Diante dessa situação, o uso da categoria 'grupos conservadores' aponta a uma posição compreensiva (...) e permite entender as referidas estratégias práticas à luz das transformações" (MUJICA, 2011, p. 94-95).
} 
como conceito filosófico ou semântico (SEMPRINI, 1999, p.11). A diferença é antes de tudo uma realidade concreta, um processo humano e social que insere os indivíduos em suas práticas cotidianas a partir de um processo histórico. É, pois, necessário pensar, entender, refletir a partir da diferença assumindo uma nova postura.

O indivíduo ou o grupo não são sujeitos quando pairam sobranceiros acima das condutas práticas. O sujeito é mais forte e mais consciente de si mesmo quando se defende contra ataques que ameaçam sua autonomia e sua capacidade de perceber-se para reconhecer-se e ser reconhecido como tal (...). O sujeito não é apenas aquele que diz eu, mas aquele que tem a consciência de seu direito de dizer eu. É por isso que a história social é dominada pela reivindicação de direitos: direitos cívicos, direitos sociais, direitos culturais, cujo reconhecimento é exigido hoje de maneira tão premente que constituem campo mais delicado no mundo em que vivemos (TOURAINE, 2006, p. 112-113).

A "epistemologia multicultural" traz à tona as contradições da sociedade brasileira que tantas vezes se professou universalista e igualitária, ${ }^{3}$ mas, que diante dos questionamentos multiculturais, descobre-se profundamente marcada pelas desigualdades. Em última instância, o que está em jogo nesta dinâmica é o projeto de uma sociedade construída de acordo com as premissas da globalização e da modernidade. Infelizmente a "análise monocultural (...) garante que a verdade existe e que é possível conhecê-la, que existe uma solução para cada problema e que é a ciência quem dará tal solução" (SEMPRINI, 1999, p. 89).

2 Multiculturalismo tem sido empregado para indicar o caráter plural das sociedades ocidentais contemporâneas. Compreende-se enquanto resposta aos desafios impostos à sociedade, à medida que inclui a formulação de definições conflitantes de mundo social, decorrentes de distintos interesses econômicos, políticos e sociais. Em tal formulação, as relações de poder desempenham papel relevante, auxiliando a confrontar a maneira como os indivíduos, grupos e instituições tencionam consolidar suas identidades. O multiculturalismo questiona a afirmação de que a realidade existe independente do sujeito e da linguagem utilizada. Afirmar que a realidade é uma construção e que está fortemente ligada ao sujeito e à linguagem é uma oposição direta à suposta objetividade científica preconizada na modernidade (MCLAREN, 1997).

3 Gilberto Freyre foi um dos pioneiros do "mito da democracia racial" apregoando que existiria, no Brasil, a igualdade de oportunidades para brancos, negros e mestiços. A disseminação desse mito permitiu esconder desigualdades raciais, que ainda podem ser constatadas nas práticas discriminatórias de acesso ao emprego, nas dificuldades de mobilidade social da população negra e que recebe remuneração inferior à do branco pelo mesmo trabalho e tendo a mesma qualificação profissional. A falta de conflitos étnicos não caracteriza ausência de discriminação, mas este silêncio favorece o "status quo" que, por sua vez, beneficia a classe dominante (FREYRE, 2001). 
A consolidação de parâmetros para uma convivência que motive a pensar na perspectiva da inclusão remete para o exercício da compreensão e do respeito mútuo. Se a convivência se encontra centrada na dominação cultural de um grupo ou de uma corrente ideológica, será preciso perceber o multiculturalismo como o caminho para reconhecer a alteridade e o direito à diferença dos grupos que se sentem excluídos do processo social.

A grande questão do multiculturalismo reside no fato de respeitar as identidades, convivendo com o diferente (...). O multiculturalismo apregoa o respeito das diferenças (...) sendo importante, inclusive, encorajar as particularidades buscando (...) a política de igual dignidade entre os seres humanos... (ANGELIN, 2010, p. 30).

Ao defender-se a existência de uma verdade imposta a toda coletividade mesmo sabendo que existam direitos absolutos, princípios jurídicos muito relevantes são desconsiderados. (EMMERICK, 2013, 278-279). Os direitos somente podem ser garantidos com a proibição de imposições de moralidades religiosas hegemônicas.

A forte atuação de grupos religiosos conservadores no parlamento brasileiro busca garantir algumas prerrogativas morais e teológicas na regulação jurídica no tocante aos direitos relacionados à família, sexualidade, reprodução e aborto. O reconhecimento da sexualidade e da reprodução como direito humano ainda é algo bastante recente. Tal fato redunda em uma prevalência do senso comum e de tabus na sociedade em geral.

O crescimento dos movimentos feministas e os ganhos na criação de leis que regulamentam o aborto e a implementação de políticas publicas referidas a direitos sexuais e reprodutivos, ao lado da expansão dos direitos das mulheres indicaram que novos valores se fazem presentes na sociedade contemporânea (MACHADO, 2008, p. 243).

O grande desafio é o de pensar a religião no contexto dos conflitos da contemporaneidade e de compreender que a cultura e as identidades acabam se articulando de forma estratégica com a democracia, a diversidade e os direitos (BOFF, 2006). A religião acaba sendo parte da emergência de uma cultura e condicionada pelos embates e conflitos decorrentes do pluralismo, da intolerância e da consolidação de políticas democráticas. 
A questão não é mais, pelo menos num futuro próximo, se 'a religião' deve estar presente na esfera das instituições públicas, mas como dar sentido a esta presença, como perceber suas diferentes modalidades, impactos e fontes e como avaliar as distintas implicações das relações entre esses atores (e mesmo projetos) religiosos e seus interlocutores e adversários não religiosos (BURITY, 2008, p. 93).

É preciso sublinhar que a reconfiguração da democracia no Brasil, ainda que de forma incipiente, produziu avanços e gerou modificações importantes nas estruturas políticas. Houve mobilização e abertura para que surgissem novos agentes. Neste contexto foram sendo demarcados fluxos, instaurados intercâmbios e ampliados domínios. Foram surgindo novas vozes que estenderam a repercussão de temas concernentes à diversidade de gênero, sexual, cultural, ética e, também, souberam repercutir as demandas pela garantia de políticas de convivência e alteridade, consolidação de direitos e tolerância (SORJ, 2001).

As mudanças ocorridas no âmbito do processo político brasileiro, com modificações nas estruturas do Estado que induziram para uma relativa descentralização dos capitais, a expansão da democracia e dos direitos humanos forçou os grupos conservadores a construir um discurso público tendo como premissa os ideais em torno da defesa da vida. Houve uma mudança estratégica de ação e discurso que tem consolidado:

A participação de novos atores políticos (...). Um interesse dos meios de comunicação no tema dos direitos, exclusão, democracia, justiça em que as formas clássicas de exclusão (...), apesar de ser uma prática que não foi eliminada dos imaginários e das relações sociais, já não são legitimados pelos discursos políticos. Produz-se uma fenda na correlação entre as elites, isto é, entre o controle dos grupos conservadores e o Estado. (...) Novos atores, novos processos e um sistema diferente, diante do qual tem de elaborar novas maneiras de penetração e controle (MUJICA, 2011, p. 91).

Há uma efetiva preocupação não apenas em relação ao discurso, mas, sobretudo, com estratégias práticas e ações efetivas nos espaços de interação social. Desta maneira, o que ocorre é uma permanente e obstinada busca por influir no espaço público visando consolidar determinadas leis, subjugar políticas públicas de inclusão das minorias, criticar materiais educacionais produzidos pelo Estado de modo a garantir e ampliar o horizonte dos direitos constitucionais. 
Em suma, os grupos conservadores se transformaram. Reconstruíram-se politicamente em uma reação diante da secularização. No entanto, esta transformação não foi única. Esses grupos têm (...) reconstruindo seus discursos e seus conceitos para se adaptarem às mudanças políticas e econômicas nos últimos séculos (...). A inserção na política partidária, nas direções, nos movimentos político-sociais de base mostra que são grupos dinâmicos, diferentes das sociedades herméticas que se têm imaginado regularmente. $O$ ativismo conservador inseriu-se no debate da democracia formal utilizando seus procedimentos. Nessa inserção formou agrupamentos laicos e aprendeu a ser estrategicamente secular. $\mathrm{O}$ assunto é que é preciso reconhecer que o ativismo conservador também é parte da democracia, de seus procedimentos e de seus mecanismos de demanda (MUJICA, 2011, p. 95-96).

Esta adequação contextual dos grupos conservadores traz à tona um deslocamento dentro da sociedade civil organizada. Consolida-se uma agenda de trabalho e de incidência pública através de grupos profissionais especializados e de forças políticas que, embora não se valham explicitamente das referências do conservadorismo religioso, manifestam-se contrários a temas como os relacionados aos direitos sexuais e reprodutivos. ${ }^{4}$

4 É comum a superação da formalidade partidária ou da dicotomia ideológica entre direita e esquerda. Os partidos não determinam as demandas conservadoras e nem delimitam temas. Os grupos conservadores têm ampliado sua estratégica através da criação de associações formadas por profissionais especializados, como, por exemplo, de médicos, engenheiros, profissionais liberais, professores universitários e advogados. No âmbito jurídico, uma das mais atuantes entidades brasileiras é a Associação Nacional de Juristas Evangélicos - ANAJURE. Fundada no ano de 2012 e tendo como lema a defesa das liberdades civis fundamentais, afirma a sua atuação através da sua declaração de princípios, representações estaduais, conselho consultivo, assessoria internacional, tradutores, convênios com universidades da Europa e América Latina, congressos, publicações, formação, propostas de políticas públicas e projetos de lei, assistência judiciária gratuita e parceria com quase 50 igrejas e entidades. As mais conhecidas são a Convenção Batista Brasileira, Igreja Adventista do Sétimo Dia, a Igreja de Jesus Cristo dos Santos dos Últimos Dias, Igreja Evangélica Luterana no Brasil (IELB), Conferência Nacional dos Bispos do Brasil (CNBB), Igreja Metodista do Brasil, Igreja Presbiteriana do Brasil, Sociedade Bíblica do Brasil (SBB), Associação Brasileira de Instituições Educacionais Evangélicas (ABIEE), Universidade Luterana do Brasil (ULBRA), Universidade Presbiteriana Mackenzie. Sua missão é a defesa das liberdades civis fundamentais - em especial a liberdade religiosa e de expressão - e a promoção dos deveres e direitos humanos fundamentais - em especial o princípio da dignidade da pessoa humana, tudo isso sob a égide e as bases do Cristianismo e do seu consectário histórico, o Estado Democrático de Direito. Entre os seus objetivos principais está o de constituir-se como uma entidade de auxílio e defesa administrativa e jurisdicional das igrejas e denominações evangélicas, em especial, nos casos de violação dos direitos fundamentais de liberdade religiosa e de 
A defesa da vida aparece como uma estratégia política e discursiva moralmente efetiva, mas tem problemas quando se aproxima da prática concreta das pessoas. Não pode superar o problema da mortalidade materna, os problemas de debate sobre a vida digna, a demanda no uso de contraceptivos, a tendência à descriminalização do aborto (MUJICA, 2011, p. 98).

A percepção da magnitude do ativismo conservador por parte daqueles e daquelas que lutam em favor dos direitos sexuais e reprodutivos se deve, em grande medida, pelo fato de que são atores que ocupam vários espaços de maneira individual, em situações estratégicas de decisão política, mas, também, pela expressiva utilização dos espaços da tecnologia virtual, maximizando pautas.

Sinteticamente, o que se percebe é que 9...) tem como objetivo principal combater as ações (...) que visam avançar na garantia dos direitos sexuais e reprodutivos, bem como barrar toda e qualquer ação ou projeto de lei que afronte os princípios morais e religiosos sobre a vida e a família. (...) tem posicionamentos divergentes no que diz respeito aos mais diferentes temas, mas, em relação às temáticas relacionadas ao aborto, tem um posicionamento convergente, ou seja, se opõem a toda e qualquer ação que vise descriminalizar ou aumentar os permissivos legais do aborto, por considerar que a vida inicia-se no momento da concepção (EMMERICK, 2013, p. 214-215).

No contexto da sociedade brasileira contemporânea o que é possível observar é uma demanda por inserção política de grupos religiosos, alicerçados na reconfiguração de premissas teológicas, através da militância, do engajamento e dos discursos políticos. Talvez a grande disputa na construção dos direitos sexuais e reprodutivos, no espaço público brasileiro, nem seja a reafirmação da neutralidade das instituições republicanas, mas, constituir meios adequados para incorporar os conflitos inerentes às lógicas culturais e religiosas nos debates públicos (ROSADO-NUNES, 2008, p. 67-81).

expressão; constituir-se como um fórum nacional de discussão sobre o ordenamento jurídico brasileiro, sobre os projetos de lei em tramitação, sobre as propostas de políticas públicas governamentais, especialmente no que diz respeito aos deveres e direitos humanos fundamentais (Associação Nacional de Juristas Evangélicos - ANAJURE. Disponível em: http://www.anajure.org.br/. Acesso em: 12 fev. 2016). 


\section{A Construção dos Direitos Sexuais e Reprodutivos no Espaço Público Brasileiro}

Falar sobre a possibilidade plena do exercício da autonomia e cidadania, ou seja, falar de direitos, também significa a possibilidade de expressar e exercer, sem coerção, desejos, afetos, relações amorosas, sem discriminação, sem violência. Como aludido por Sonia Corrêa, ao falar de igualdade como um dos marcos da autodeterminação e do exercício dos direitos sexuais e reprodutivos, é preciso levar em conta que a premissa da igualdade de tratamento perante a lei, no que se refere à sexualidade, deve garantir que:

...independente de como são os seres humanos, de que superfícies anatômicas apresentam, de que práticas sexuais preferem ou exercem, eles e elas devem receber o mesmo tratamento perante a lei em casa, no local de trabalho e nas demais instituições (CORRÊEA, 2001, p.21).

Desenvolver a ideia de direitos sexuais e reprodutivos, na perspectiva dos direitos humanos, aponta para a possibilidade do exercício livre e responsável da sexualidade, criando as bases para uma regulação jurídica que supere as tradicionais abordagens repressivas que caracterizam as intervenções jurídicas nesses domínios (LOREA; KNAUTH, 2010).

Cabe destacar que, no decorrer da história, ${ }^{5}$ os processos de determinação cultural das diferenças sexuais foram sendo produzidos em contextos de poder e conflitos que consideravam relações produtoras de práticas discursivas sobre o sexo (SCO'T'T, 1994). A partir desta perspectiva acabaram instituindo

Estudos antropológicos, históricos e também no âmbito da teologia mostram que a punição ao aborto, durante os seis primeiros séculos do cristianismo, não era referida, em primeiro lugar, ao feto cuja vida seria tirada, mas ao adultério que o aborto revelaria. A preocupação central tanto da Igreja como do Estado era o casamento monogâmico como regra para toda a sociedade. O primeiro concílio do Ocidente, realizado no século IV, antes mesmo da oficialização do cristianismo por Constantino, estabeleceu penas religiosas para as transgressões à fidelidade conjugal. As penas impostas pelo Estado e pela Igreja eram mais duras para os casos de adultério do que para os de homicídio. Tomás de Aquino sugeria que o aborto seria criminoso apenas quando o feto estivesse completamente formado. Ele admitia o aborto até oitenta dias após a concepção, argumentando que até esse momento a alma não havia sido implantada no feto dentro do útero da mulher. Não havendo alma, não haveria vida humana. Essa compreensão predominou até o século XIX, quando o papa pio IX, em 1869, declarou que o aborto era pecado em qualquer situação. Com isso, rechaçou-se a teoria da hominiz̧ação retardada para assumir a da hominiz̧ação imediata, isto é, a tese de que, desde o momento da concepção, existiria um ser humano e, portanto, atentar contra a vida redundaria em homicídio (HURST, 1992, p. 7-40). 
individualidades e instaurando dessimetrias nas quais houve a 'naturalização' das diferenças sexuais (PERRO'T, 2015, p. 62-80).

Simone de Beauvoir (1970) soube descortinar, de forma contundente, as relações de gênero ao denunciar como a sociedade foi definindo a representação masculina, de forma destacada e positiva, a partir da perspectiva patriarcal e androcêntrica. Caberia às mulheres os lugares da maternidade, do cuidado da família e da vida privada, da não razão. Tal argumento estaria embasado numa suposta natureza que englobaria características morais, psicológicas e racionais que justificariam a sua permanência em determinados espaços sociais. ${ }^{6}$

A antropóloga Marcela Lagarde y de los Ríos (2011) refere que existe uma naturalização dos papéis das mulheres, no âmbito das sociedades patriarcais, a partir de determinadas condições biológicas que justificam o exercício de relações arbitrárias de poder e opressão. As mulheres não são instruídas e nem estimuladas a exercitar sua autonomia e os seus direitos. Para a autora, os círculos de vida ou cativeiros reforçam estereótipos. Ela cita, pelo menos, cinco características: "madresposas" são aquelas que exercitam os papéis da maternidade, da filiação e do matrimônio; "monjas" são as que estabelecem vínculos conjugais sublimados pela dimensão divina. Vivem a relação de dependência sagrada no serviço e na adoração incondicional pela fé; "putas" concretizam aquilo que é social e moralmente proibido. O desejo negado, a poligamia; "presas" vivem a privação da liberdade na perspectiva material e simbólica. A casa é o local desta privação e também o exemplo a ser seguido; "loucas" personificam a dimensão genérica negativa presente nas mulheres.

Assim, todas as mulheres estão cativas de seu corpo-para-outros, procriador ou erótico, e de seu ser-de-outros, vivendo com sua necessidade de estabelecer relações de dependência vital e de sujeição ao poder e aos outros. Todas as mulheres, no bem ou no mal, definidas pela norma, são politicamente

\footnotetext{
Rousseau, na constituição do Estado Moderno, por exemplo, apresenta a função da mulher no contrato social de modo a garantir uma inserção bem sucedida do homem no mundo público. Suas atividades consistiriam na construção das bases para esta inserção. As mulheres dependem da opinião masculina. São, inclusive, objetos do pacto patriarcal. "Aos homens importa cultivar uma faculdade que sirva de árbitro (...), que não deixe que a consciência se perca que corrija os erros dos preconceitos. Essa faculdade é a razão. Mas diante dessa palavra, quantas questões se levantam! São capazes as mulheres de levantar pelo menos um argumento? É importante que elas cultivem essa capacidade? Podem fazê-lo com êxito? Essa cultura é útil para as funções que lhe são impostas? É compatível com a simplicidade que lhes convém?" (ROUSSEAU, 1970, p. 306).
} 
inferiores aos homens e entre elas. Pelo seu ser-de e para-outros, definem-se filosoficamente como seres incompletos, como territórios, prontos para serem ocupadas e dominadas pelos outros em um mundo patriarcal (LAGARDE Y DE LOS RÍOS, 2011, p. 41; tradução nossa). ${ }^{7}$

Silvia Camurça, em uma leitura instigante acerca de uma possível práxis educacional para a promoção de uma reflexão entre as mulheres, suscita questionamentos importantes. Um deles é "a ideia de que as mulheres são subjetivamente oprimidas e objetivamente exploradas"; e também que "essa opressão e exploração acontece nas relações sociais" (Camurça, 2007). Por isso, a dominação não se faz do mesmo jeito sobre todas as mulheres. Pode variar, por exemplo, em "classes e por identidade étnico-racial." A autora denuncia os mecanismos que sustentam e sobre os quais se reinventa o sistema de dominação, a saber:

A prática da violência contra as mulheres para subjugá-las; O controle sobre o corpo, a sexualidade e a vida reprodutiva das mulheres; A manutençãodas mulheres em situação de dependência econômica; A manutenção, no âmbito do sistema político e práticas sociais, de interdições à participação política das mulheres. (...) como instrumento de dominação e controle sobre o corpo das mulheres. Este controle é expresso na negação de sua liberdade sexual, na limitação a sua autodeterminação reprodutiva, na criminalização da prática do aborto (causa de milhares de mortes de mulheres, todos os anos) na expropriação mercantil do corpo e imagem das mulheres pela indústria da propaganda, da beleza, da moda e do sexo (CAMURÇA, 2007, p. 19 e 20).

A luta por liberdade sexual e pelo direito de decidir sobre os corpos, longe de ser específica, assume um caráter central para os movimentos que almejam a transformação social. Uma história marcada por enredos, por vivências pessoais e coletivas da sexualidade e da reprodução, ancorados em contextos e processos históricos onde a violência sempre foi um elemento impactante e regulador (EISLER, 2007).

O termo "direitos reprodutivos" tornou-se mais conhecido no primeiro Encontro Internacional de Saúde da Mulher realizado em Amsterdã, na Ho-

\footnotetext{
7 Así, todas las mujeres están cautivas de su cuerpo-para-otros, procreador o erótico, y de su ser-de-otros, vivido como su necesidad de establecer relaciones de dependencia vital y de sometimiento al poder y a los otros. Todas las mujeres, en el bien o en el mal, definidas por la norma, son políticamente inferiores a los hombres y entre ellas. Por su ser-de y para-otros, se definen filosóficamente como entes incompletos, como territorios, dispuestas a ser ocupadas y dominadas por los otros en el mundo patriarcal.
} 
landa, em 1984. Contudo, foi na Conferência Internacional da Organização das Nações Unidas sobre População e Desenvolvimento (CIPD), no Cairo, em 1994, que foi conferido papel determinante e primordial à saúde, aos direitos sexuais e aos direitos reprodutivos, ultrapassando objetivos demográficos e objetivando o desenvolvimento dos seres humanos. A CIPD provocou uma transformação profunda no debate populacional ao dar prioridade às questões dos direitos humanos (BUSIN, 2013, p. 19).

A Plataforma de Ação do Cairo além de introduzir o conceito de direitos reprodutivos, sinalizou para o reconhecimento de direitos sexuais, destacando o direito de exercer a sexualidade e a reprodução livre de discriminações, coerções e violências. Também estimulou e promoveu as diretrizes para o relacionamento respeitoso e igualitário entre homens e mulheres, dando atenção especial a segmentos populacionais mais vulneráveis às violações de direitos humanos nos campos da reprodução e da sexualidade. No seu capítulo VII, os direitos reprodutivos estão definidos da seguinte forma:

Os direitos reprodutivos abrangem certos direitos humanos já reconhecidos em leis nacionais, em documentos internacionais sobre direitos humanos, em outros documentos consensuais. Esses direitos se ancoram no reconhecimento do direito básico de todo casal e de todo indivíduo de decidir livre e responsavelmente sobre o número, o espaçamento e a oportunidade de ter filhos e de ter a informação e os meios de assim o fazer, e o direito de gozar do mais elevado padrão de saúde sexual e reprodutiva. Inclui também seu direito de tomar decisões sobre a reprodução, livre de discriminação, coerção ou violência (CARTILHA, 2005, p. 6-7).

A partir da assertiva de que a sexualidade e a reprodução são elementos inerentes à vida humana, torna-se imprescindível consolidar mecanismos legais que garantam a liberdade do seu exercício.Em uma tentativa de responder à possibilidade de construção de direitos no âmbito da sexualidade,Betânia Ávila elucida alguns elementos importantes para a discussão:

O que é muito novo nos direitos reprodutivos e sexuais é o fato de serem inventados, pensados e reivindicados pelas mulheres. As mulheres não são, por tradição, inventoras de direitos; elas são guardiãs de normas. A ideia de direitos no campo da sexualidade é algo importante e muito novo,uma vez que a concepção de direito está ligada à garantia de autonomia, de liberdade e de igualdade 9...).Então, pensar direitos é pensar uma mudança profunda, também do ponto de vista da transformação cultural do próprio exercício do erotismo (...). Dito de outra maneira: é necessário um exercício filosófico 
que nos possibilite pensar novos símbolos de igualdade neste campo (ÁVILA, 2001 p.13).

Observando a partir da perspectiva dos direitos há que se reconhecer o campo da sexualidade e da reprodução como esfera para a construção de princípios jurídicos ainda a serem reconhecidos. Falar dos direitos sexuais e direitos reprodutivos sob o marco dos direitos humanos ${ }^{8}$ significa aceitá-los como universais, interdependentes e indivisíveis (BUSIN, 2013, p. 12).

Ao fazer uma coletânea das disposições constitucionais correlatas aos direitos sexuais e reprodutivos no caso do Brasil, Miriam Ventura observa:

A Constituição define (...) a igualdade de direitos e deveres na sociedade conjugal. Sob a denominação de planejamento familiar, garante a norma constitucional um conjunto de direitos ligados à reprodução humana, fundados no princípio da dignidade da pessoa humana e da paternidade responsável, atribuindo ao Estado o dever de propiciar os recursos educacionais e científicos para sua promoção, e garantir seu exercício sem coerção ou violência (VENTURA, 2002, p. 101).

Isto significa dizer, que mesmo tendo a saúde maior ênfase como o arcabouço da construção dos direitos sexuais e reprodutivos, a efetivação dos mesmos deve ocorrer em conexão com outros campos da vivência da cidadania, como o contexto político, as dimensões culturais, para além de normas legais e como prerrogativa de autonomia e liberdade dos sujeitos humanos nas esferas da sexualidade e reprodução (CORRÊA, 2001).

A luta em favor dos direitos sexuais e reprodutivos é parte de uma agenda democrática de direitos. Reconhecer as demandas das mulheres como sujeitos políticos e éticos na tomada de decisões sobre seus projetos de vida é essencial para aprimorar os contornos de uma sociedade inclusiva e que exercite a cidadania plena (BATISTA e JÁCOME, 2014, p. 93-102). No momento em que os movimentos de mulheres apresentam suas reivindicações dentro de um marco de direitos, afirma-se um patamar mínimo sobre o qual devem sustentar-se as relações sociais.

8 Com certa frequência os direitos humanos são formalizados e garantidos legalmente através de tratados no âmbito do direito internacional consuetudinário de modo a estabelecer obrigações aos governos, orientar políticas públicas, proteger as liberdades fundamentais de indivíduos ou grupos sociais. O direito consuetudinário é baseado em costumes presentes em determinadas sociedades. Nele, as leis não necessitam ser escritas ou passar por processos formais de codificação. Os próprios costumes acabam consolidando a legislação (CURI, 2012, p. 230-247). 
Valorizar a autonomia é fundamental diante do reconhecimento de que os indivíduos não possuem as mesmas condições para acessar e exercer os direitos, pois são condicionados por processos históricos de opressão, discriminação, dominação e exploração, moldados por diversas questões de ordem cultural, étnica e religiosa (LE GOFF, 1995). Compete ao Estado e, portanto, às instituições do Poder Público, garantir que todas as pessoas possam exercer livremente seus direitos sexuais e reprodutivos, situados no marco normativo político e conceitual dos direitos humanos (MORI, 1997).

O filósofo e sociólogo alemão, Jürgen Habermas (2007), conhecido pela defesa das teorias da racionalidade comunicativa e da esfera pública, reitera que, na sociedade contemporânea, o Estado regido pelo constitucionalismo democrático deveria garantir a sua sustentação com base na participação simétrica dos indivíduos enquanto atores e, ao mesmo tempo, destinatários das leis. Refere que os resultados da participação política deveriam ser aceitáveis pelo conjunto dos cidadãos e cidadãs.

O procedimento democrático extrai sua força geradora da legitimação de dois componentes, a saber: da participação política simétrica dos cidadãos, a qual garante aos destinatários das leis a possibilidade de se entenderem, ao mesmo tempo, como autores; e da dimensão epistemológica de certas formas de uma disputa guiada discursivamente, as quais fundamentam a suposição de que os resultados são aceitáveis em termos racionais. As expectativas e os modos de pensar e de se comportar dos cidadãos, que não podem ser simplesmente impostas mediante o direito, podem ser, no entanto, explicitadas a partir desses dois componentes da legitimação. As condições para uma participação bem-sucedida na prática comum de autodeterminação definem o papel do cidadão no Estado: os cidadãos devem respeitar-se reciprocamente como membros de sua respectiva comunidade política dotados de iguais direitos, apesar de seu dissenso em questões envolvendo convicções religiosas e visões de mundo (HABERMAS, 2007, p. 136).

A inserção dos grupos conservadores na esfera pública implica a perspectiva de negação do pluralismo. A defesa de uma premissa religiosa, tal como o direito a vida desde a concepção, implica em um aviltamento de outras compreensões morais, e, sobretudo, uma transgressão do poder público quanto ao principio de neutralidade do Estado com respeito aos distintos credos, um requisito da democracia (COSTA, 2008).

O conservadorismo religioso no Brasil tem conseguido atuar politicamente, na maioria das vezes, não como participante ou promotor de um 
debate entre distintas forcas políticas e cidadãs, mas, muito mais no sentido de alcançar determinadas demandas arbitrárias ${ }^{9}$ na esfera de instituições democráticas. Há uma intervenção aberta através da eleição de representantes em posições legislativas e executivas.

O efetivo exercício de direitos abarca uma transformação da lógica na qual está baseado o sentido das leis que dizem respeito ao exercício da reprodução e das relações sexuais (RIOS, 2014). Uma transformação que indica na direção de um deslocamento da lógica da prescrição e controle para o princípio da ética e da liberdade. As políticas públicas orientadas para as demandas de direitos deveriam estar pautadas com vistas à concretização da justiça social (CORREGIDO, 2004). Neste sentido, necessitam ser formuladas e executadas levando em conta as desigualdades de gênero, de classe, de raça e de expressão sexual.

\section{Considerações Finais}

As reflexões acerca dos direitos sexuais e reprodutivos no contexto brasileiro contemporâneo são permeadas pela complexidade que envolve a construção da laicidade em um ambiente onde os paradigmas religiosos servem como instrumentos de influência política no Estado, através de hierarquias organizadas e com poder de barganha junto aos legisladores e membros do executivo, ou como forma de instrução capaz de disciplinar a opinião pública.

No Brasil, vive-se um momento de redefinição e reformulação da agenda de direitos humanos, em que são incorporados temas como os direitos econômicos, sociais e culturais, ao lado dos tradicionais direitos civis e políticos. Neste cenário, é primordial agregar os direitos sexuais e reprodutivos como direitos humanos, com base nos parâmetros internacionais e constitucionais. Há que se deixar de lado extremismos religiosos ou laicos

\footnotetext{
9 A proposta legislativa n 4 $^{\circ} / 2007$ conhecida como "Estatuto do Nascituro" é um reflexo desta persuasão política dos grupos conservadores na Câmara Federal. A proposta incide sobre a vida desde a sua concepção, ao criar deveres ao Estado, à família e à sociedade no sentido de garantir a inviolabilidade da vida e proibir o aborto em qualquer hipótese, institucionalizando o controle sobre a vida e os corpos das mulheres. Contradiz os direitos da mãe contemplados no Código Penal ao tratá-lo como questão de política criminal, ao invés de entendê-lo como problema de saúde pública. Com clara influência religiosa, o estatuto afronta o princípio da laicidade do Estado ao difundir uma determinada concepção religiosa acerca do início da vida, seu valor, a autonomia das mulheres, a liberdade e a igualdade (ANGELIN, 2015b, p. 182-198).
} 
em detrimento da tolerância, do diálogo e do mútuo aprendizado entre os diversos protagonistas que articulam o debate.

A atuação de atores religiosos no espaço público, em relação a temas controversos do ponto de vista da moralidade religiosa, tem sido paradoxal e ambígua. Numa sociedade diversa, multicultural e democrática como a brasileira, a participação de diferentes grupos na consolidação de políticas públicas e na regulação jurídica pode ser legítima e positiva, desde que sejam estabelecidas regras nas quais os argumentos religiosos sejam traduzidos para o âmbito constitucional de modo a orientar a defesa e a preservação dos direitos humanos.

Por fim, o efetivo exercício dos direitos sexuais e reprodutivos, sob a perspectiva dos direitos humanos, demanda ações políticas, jurídicas, emancipatórias, criativas e transformadoras para assegurar aos indivíduos o exercício de sua sexualidade e de sua capacidade reprodutiva, com plena autonomia e dignidade. A transformação das mentalidades é um processo essencial à vivência de direitos. Estes, por sua vez, trazem consigo a prerrogativa de construção de um novo imaginário social sobre os temas dos quais eles tratam.

\section{Referências}

ANAJURE. Associação Nacional de Juristas Evangélicos. Disponível em: http://www. anajure.org.br/. Acesso em: 12 fev. 2016.

ANGELIN, Rosângela. O Reconhecimento da Identidade Multicultural diante da Dignidade da Pessoa Humana. In: MADERS, Angelita; ANGELIN, Rosângela. (Org.). Multiculturalismo em Foco. Santo Ângelo: FuRI, 2010. p. 21-34.

- Direitos sexuais e direitos reprodutivos das mulheres: avanços e desafios na construção da democracia. Coisas do Gênero, v.1, n. 2, p. 182-198, dez. 2015b. ÁVILA, Maria Betânia. Os Direitos Sexuais Devem Ser uma Pauta Constante do Feminismo (Entrevista). In: Jornal da Rede Saúde. n. 24, p. 11-17, dez. 2001.

BARBOSA, Rui. Obras Completas, Vol. 4. Tomo 1, O Papa e o Concílio. Rio de Janeiro: Fundação Casa de Rui Barbosa, 1877.

BATISTA, Carla Gisele; JÁCOME, Márcia Laranjeira. Conservadorismo no Brasil: modos de atuação e estratégias ofensivas aos direitos sexuais e direitos reprodutivos. In: OROZCO, Yury Puello. (Org.) A Presença das Mulheres nos Espaços de Poder e Decisão. São Paulo: Católicas pelo Direito de Decidir, p. 93-102. Ago. 2014.

BEATY, David M. A Essência do Estado de Direito. São Paulo, Martins Fontes, 2014.

BEAUVOIR, Simone de. O Segundo Sexo. Vol. I (Fatos e Mitos). São Paulo: Difusão Europeia do Livro, 1970. 
BERGER, Peter. O dossel sagrado. Elementos para uma teoria sociológica da religião. São Paulo: Paulus, 2004.

BOFF, Leonardo. Virtudes para um outro mundo possível. Convivência, respeito e tolerância. Petrópolis, Vozes, 2006.

BURITY, Joanildo A. Religião, Política e Cultura. Tempo Social, v. 20, n. 2. p. 83-113. 2008.

BUSIN, Valéria Melki.. (Org.). Direitos Humanos para Ativistas por Direitos Sexuais e Direitos Reprodutivos. São Paulo: Secretaria de Políticas para Mulheres/ Católicas pelo Direito de Decidir, 2013.

CAMURÇA, Silvia. "Nós mulheres e nossa experiência comum". Cadernos de Critica Feminista, ano 1, n. 0, p. 12-25, 2007.

CANOTILHO, José Joaquim Gomes. Direito Constitucional. Coimbra: Livraria Almedina, 1993.

CARTILHA. Direitos Sexuais e Reprodutivos. Prioridade do Governo. Disponível em: http://bvsms.saude.gov.br/bvs/publicacoes/cartilha_direitos_sexuais_reprodutivos.pdf. Acesso em: 15 fev. 2016.

CATROGA, Fernando. Entre deuses e césares: secularização, laicidade e religião civil. Coimbra: Almedina, 2006.

CORRÊA, Sonia. Gênero e Sexualidade: deslocando o debate da margem para o centro, Jornal da Rede Saúde. n. 24, p. 30-34, dez. 2001.

CORREGIDO, Maria Dolores Juliano. Excluídas y Marginales. Madrid: Cátedra Instituto de La Mujer, 2004.

COSTA, Maria Emília Corrêa da. Apontamentos sobre a liberdade religiosa e a formação do Estado Laico. In: LOREA, Roberto Arriada. (Org.). Em defesa das Liberdades Laicas. Porto Alegre: Livraria do Advogado, 2008. p. 97-116.

CURI, Melissa Volpato. O Direito Consuetudinário dos Povos Indígenas e o Pluralismo Jurídico, Espaço Ameríndio, v. 6, n. 2, p. 230-247, jul./dez. 2012.

DAMATTA, Roberto. O que faz o Brasil, Brasil? Rio de Janeiro: Rocco, 1986.

EISLER, Riane. O Cálice e a Espada. Nosso passado, nosso futuro. São Paulo: Palas Athena, 2007.

EMMERICK, Rulian. Religião e Direitos Reprodutivos. O Aborto como Campo de Disputa Política e Religiosa. Rio de Janeiro: Lumen Juris, 2013.

FISCHMANN, Roseli. Estado Laico. São Paulo: Memorial da América Latina, 2008.

FONSECA, Francisco Tomazoli da. Religião e Direito no Século XXI: A Liberdade Religiosa no Estado Laico. Curitiba: Juruá, 2013.

FREYRE, Gilberto. Interpretação do Brasil. São Paulo: Cia das Letras, 2001.

GALDINO, Elza. Estado sem Deus. A Obrigação da Laicidade na Constituição. Belo Horizonte: Del Rey, 2006. 
HABERMAS, Jürgen. Entre naturalismo e religião: estudos filosóficos. Rio de Janeiro: Tempo Brasileiro, 2007.

HERVIEU-LÉGER, Daniele. O peregrino e o convertido - a religião em movimento. Petrópolis: Vozes, 2008.

HURST, Jane. A História das Ideias sobre o Aborto na Igreja Católica. In: HURST, J. e MURARO, R.M. Uma História Não Contada. Montevideo: Catolicas por el Derecho a Decidir, 1992, p. 7-40.

LAGARDE Y DE LOS RIOS, Marcela. Los cautiverios do las mujeres: maadresposas, monjas, putas, presas y locas. México D.F.: Universidad Nacional Autónoma de México. 2011.

LE GOFF, Jacques. O Nascimento do Purgatório. Lisboa: Editorial Estampa, 1995.

LEITE, Fábio Carvalho. Estado e Religião. A Liberdade Religiosa no Brasil. Curitiba: Juruá, 2014.

LOCKE, John. Carta a Respeito da Tolerância. São Paulo: Ibrasa, 1964.

LOREA, Roberto Arriada; KNAUTH, Daniela Riva. Cidadania Sexual e Laicidade. Um estudo sobre a influência religiosa no Poder Judiciário do Rio Grande do Sul. Porto Alegre: Livraria do Advogado, 2010.

LUCKMANN, Thomas. A Religião Invisível. São Paulo: Olho d'água/Loyola, 2014.

MACHADO, Jónatas E. M. Estado Constitucional e Neutralidade Religiosa. Porto Alegre, Livraria do Advogado, 2013.

MACHADO, Maria das Dores. Religião e as assimetrias de gênero na América Latina. In: ORO, Ari Pedro. (Org). A latinidade da América Latina: enfoques sócioantropológicos. São Paulo: Aderaldo \& Rothschild, 2008. p. 241-264.

MCLAREN, Peter. Multiculturalismo crítico. São Paulo: Cortez, Instituto Paulo Freire, 1997.

MALAFAIA, Silas. Minhas Experiências de Vida. Rio de Janeiro: Editora Central Gospel, 2012.

MARTELLI, Stefano. A religião na sociedade pós-moderna: entre secularização e dessecularização. São Paulo: Paulinas, 1995.

MARTINS FILHO, Ives Gandra da Silva; NOBRE, Milton Augusto de Brito. (Coord.). O Estado laico e a liberdade religiosa. São Paulo: LTr, 2011.

MONTERO, P. \& ALMEIDA, R. O campo religioso brasileiro no limiar do século: problemas e perspectivas. In: RATTNER, H. (Org.). Brasil no limiar do século XXI. São Paulo: Edusp, 2000.

MUJICA, Jaris. Os Grupos Conservadores na América Latina. Transformações, crises, estratégias. In: JURKEWICZ, Regina Soares. (Org.). Quem Controla as Mulheres? Direitos Reprodutivos e Fundamentalismos Religiosos na América Latina. São Paulo: Católicas pelo Direito de Decidir, 2011.

MORI, Maurizio. A Moralidade do Aborto: sacralidade da vida e o novo papel da mulher. Brasília: Editora UnB, 1997. 
ORTIZ, Renato. Anotações sobre religião e globalização. Revista Brasileira de Ciências Sociais, v. 16, n. 47, p. 59-74, out. 2001.

PERROT, Michelle. Minha História das Mulheres. São Paulo: Contexto, 2015.

RIOS, Roger Raupp. Laicidade e Direitos Sexuais e Reprodutivos: Reflexões a partir dos precedentes do Supremo Tribunal federal sobre a Pesquisa com Células-Tronco, Anencefalia e Homofobia. In: RAIMUNDO, Marcia Mocellin e GUTIÉRREZ-MARTINEZ, Daniel. Bioética e Laicidade. Vida e diversidade em conexão. Curitiba; Prismas, 2014. p. 109-119.

RIVERA, Dario Paulo Barrera. Fragmentação do sagrado e crise das tradições na pós-modernidade. In: TRASFERETTI, José. (Org.). Teologia na Pós-modernidade. São Paulo: Paulinas, 2003. p. 437-464.

RODRIGUES, Eder Bomfim. Estado Laico e Símbolos Religiosos no Brasil: As Relações entre Estado e Religião no Constitucionalismo Contemporâneo. Curitiba, Juruá, 2014.

ROSADO-NUNES, Maria José Fontelas. Direitos, cidadania das mulheres e religião, Tempo Social, v. 20, n. 2, p. 67-81, nov. 2008.

ROUSSEAU, Jean-Jacques. Emílio ou da educação. São Paulo: Difusão Europeia do Livro, 1970.

SANTOS, Boaventura de Sousa. (Org.) Reconhecer para libertar: os caminhos do cosmopolitismo multicultural. Rio de Janeiro: Civilização Brasileira, 2003.

SARMENTO, Daniel. Livres e iguais: Estudos de direito constitucional. Rio de Janeiro: Lumen Juris, 2006.

O Crucifixo nos Tribunais e a Laicidade do Estado. In: Roberto

Arriada. (Org.). Em defesa das Liberdades Laicas. Porto Alegre: Livraria do Advogado, 2008. p. 189-201.

SCOTT, Joan. Debates. Cadernos Pagu, n. 3. p. 3-28, 1994. CONFERIR

SEMPRINI, Andréa. Multiculturalismo. Bauru: EDUSC, 1999

SORJ, Bernardo. A Nova Sociedade Brasileira. Rio de Janeiro: Zahar, 2001.

TOURAINE, Alain. Um novo paradigma: para compreender o mundo de hoje. Petrópolis: Vozes, 2006.

VENTURA, Miriam. Estratégias para promoção e defesa dos direitos reprodutivos e sexuais no Brasil. In: DORA, Denise Dourado. (Org.). Direito e mudança social: projetos de promoção e defesa de direitos apoiados pela Fundação Ford no Brasil. Rio de Janeiro: Renovar; Fundação Ford, 2002. p. 91-121.

WEINGARTNER, Jaime Neto. Liberdade Religiosa na Constituição: fundamentalismo, pluralismo, crenças, cultos. Porto Alegre: Livraria do Advogado, 2007.

Submetido em: 8-3-2016

Aceito em: 16-4-2017 